\title{
Single VDVTA-Based Voltage-Mode Biquad Filter
}

\author{
Ghanshyam Singh"1, Dinesh Prasad2, D. R. Bhaskar² \\ ${ }^{1}$ Department of Electronics and Communication Engineering, HMRITM, Hamidpur, Delhi, India \\ ${ }^{2}$ Department of Electronics and Communication Engineering, Faculty of Engineering and Technology, Jamia \\ Millia Islamia, New Delhi, India \\ Email: ghanshyamsingh 09@rediffmail.com, ${ }^{*}$ dprasad@jmi.ac.in, dbhaskar@jmi.ac.in
}

Received 19 February 2015; accepted 19 March 2015; published 20 March 2015

Copyright (C 2015 by authors and Scientific Research Publishing Inc.

This work is licensed under the Creative Commons Attribution International License (CC BY).

http://creativecommons.org/licenses/by/4.0/

cC) (i) Open Access

\begin{abstract}
In this paper, an application of voltage differencing voltage transconductance amplifier (VDVTA) in the realization of voltage-mode (VM) multi-input single output (MISO) type biquad is presented. The proposed topology uses one VDVTA as an active element, two capacitors and a grounded resistor. The configuration realizes low pass (LP), high pass (HP), band pass (BP) and notch (BR) filters without the requirement of any matching condition. The natural frequency $\left(\omega_{0}\right)$ and bandwidth (BW) are independently controllable. The proposed circuit offers low active and passive sensitivities of $\omega_{0}$. The operation of the proposed circuit has been verified through SPICE simulation with TSMC CMOS $0.18 \mu \mathrm{m}$ process parameters.
\end{abstract}

\section{Keywords}

Voltage Differencing Voltage Transconductance Amplifier, Analog Filter, LP, HP, BP, BR, Voltage Mode

\section{Introduction}

A number of VM MISO biquads utilizing different active elements have been proposed by the various researchers employing single active device [1]-[11]. MISO-type biquads are especially versatile because the same topology can be utilized through proper selection of input signal(s) to realize different filter functions. Such filters may be used in the implementation of touch tone telephone systems, FM stereo demodulators, phase locked loop etc. [12]. A number of new active elements have been presented in [13]. Recently Shaktour in [14] has used VDVTA in the formation of first order all pass (AP) filter. In this communication, we propose another applica-

${ }^{*}$ Corresponding author. 
tion using single VDVTA for the realization of MISO-type biquad using three inputs and one output with two capacitors and one grounded resistor. The proposed circuit realizes four basic filter functions, namely LP, HP, $\mathrm{BP}$ and BR. In the case of LP filter, the structure enjoys an extra advantage of having both the capacitors grounded as preferred for integration point of view [15]. The circuit offers the advantage of independent control of $\omega_{0}$ and $\frac{\omega_{0}}{Q_{0}}$. SPICE simulation results using TSMC CMOS $0.18 \mu \mathrm{m}$ process and $\pm 0.9 \mathrm{~V}$ DC power supply voltages verify the theoretical prediction.

\section{The Proposed Circuit Topology}

The block diagram of the VDVTA is shown in Figure 1, where $V_{P}, V_{N}$ and $V$ are input terminals and $Z$, $X^{+}$and $X^{-}$are output terminals. All terminals of VDVTA exhibit high impedance values [14]. The VDVTA can be characterised by the following terminal equations:

$$
I_{Z}=g_{m_{1}}\left(V_{V_{P}}-V_{V_{N}}\right), \quad I_{X^{+}}=g_{m_{2}}\left(V_{Z}-V_{V}\right) \text { and } I_{X^{+}}=-g_{m_{2}}\left(V_{Z}-V_{V}\right) .
$$

The circuit analysis of Figure 2 yields the following output equation in terms of input signals:

$$
V_{0}=\frac{s^{2} V_{3}+s\left(\frac{g_{m_{2}}}{C_{2}}\right) V_{2}+\left(\frac{g_{m_{1}} g_{m_{2}}}{C_{1} C_{2}}\right) V_{1}}{s^{2}+s\left(\frac{\frac{1}{R_{1}}+g_{m_{2}}}{C_{2}}\right)+\left(\frac{g_{m_{1}} g_{m_{2}}}{C_{1} C_{2}}\right)} .
$$

Through proper selection of input signal(s) from Equation (2), Figure 2 realizes the following filter functions: 1) LPF; if $V_{1}=V_{\text {in }}$ and $V_{2}=V_{3}=0$ i.e.,

$$
\frac{V_{0}(s)}{V_{\text {in }}(s)}=T_{1}(s)=\frac{\frac{g_{m_{1}} g_{m_{2}}}{C_{1} C_{2}}}{D(s)} .
$$

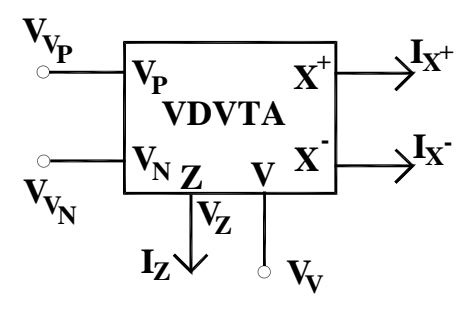

Figure 1. The symbolic notation of VDTA.

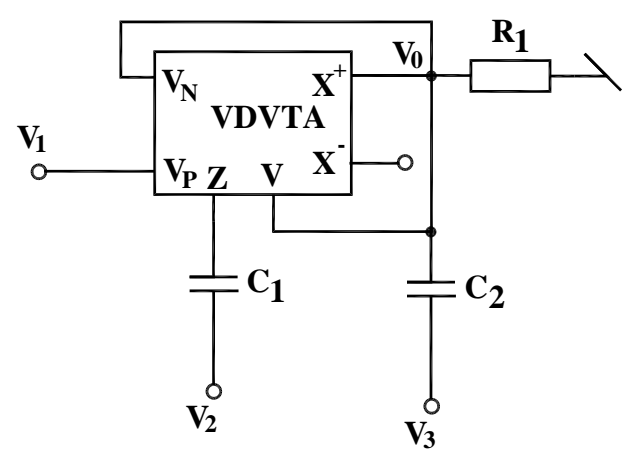

Figure 2. The proposed VM MISO-type configuration. 
2) BPF; if $V_{2}=V_{\text {in }}$ and $V_{1}=V_{3}=0$ i.e.,

$$
\frac{V_{0}(s)}{V_{\text {in }}(s)}=T_{2}(s)=\frac{s\left(\frac{g_{m_{2}}}{C_{2}}\right)}{D(s)} .
$$

3) HPF; if $V_{3}=V_{\text {in }}$ and $V_{1}=V_{2}=0$ i.e.,

$$
T_{3}(s)=\frac{V_{0}(s)}{V_{\text {in }}(s)}=\frac{S^{2}}{D(s)} .
$$

4) BRF; if $V_{1}=V_{3}=V_{\text {in }}$ and $V_{2}=0$ i.e.,

$$
T_{4}(s)=\frac{V_{0}(s)}{V_{\text {in }}(s)}=\frac{\left(S^{2}+\frac{g_{m_{1}} g_{m_{2}}}{C_{1} C_{2}}\right)}{D(s)}
$$

from Equations (3)-(6), it is clear that there is no requirement of any matching condition.

Where

$$
D(s)=s^{2}+s\left(\frac{\frac{1}{R_{1}}+g_{m_{2}}}{C_{2}}\right)+\left(\frac{g_{m_{1}} g_{m_{2}}}{C_{1} C_{2}}\right) .
$$

The natural frequency $\omega_{0}, \mathrm{BW}=\left(\frac{\omega_{0}}{Q_{0}}\right)$ and quality factor $Q_{0}$ are given by:

$$
\begin{gathered}
\omega_{0}=\sqrt{\frac{g_{m_{1}} g_{m_{2}}}{C_{1} C_{2}}} \\
\mathrm{BW}=\left(\frac{\frac{1}{R_{1}}+g_{m_{2}}}{C_{2}}\right) \\
Q_{0}=\sqrt{\frac{g_{m_{1}} g_{m_{2}} C_{2}}{C_{1}\left(\frac{1}{R_{1}}+g_{m_{2}}\right)^{2}}} .
\end{gathered}
$$

which are all low.

The sensitivities of $\omega_{0}$ with respect to passive components are found to be:

\section{Simulation Results}

To verify the theoretical prediction, the proposed circuit was simulated using CMOS VDVTA (with minor changes as shown in Figure 3) from [16]. The passive components of the proposed circuit were selected as $C_{1}=$ $0.02 \mathrm{nF}, C_{2}=0.01 \mathrm{nF}$ and $R_{1}=100 \mathrm{~K} \Omega$. The transconductances of VDVTA were controlled by bias currents. Figure 4 shows the simulated filter responses of LP, BP, HP and BR. These simulation results, thus, confirm the validity of the MISO-type proposed biquad. The comparison of proposed biquad with other available MISOtype VM-biquads with a single active element is summarized in Table 1. 


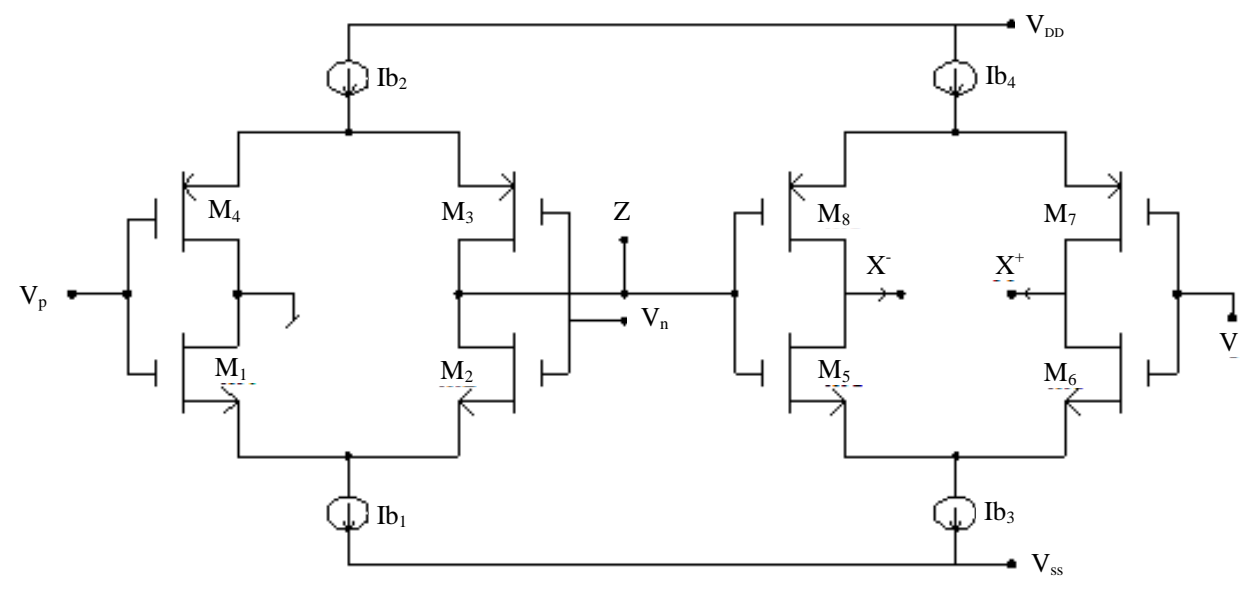

Figure 3. CMOS VDVTA [16].

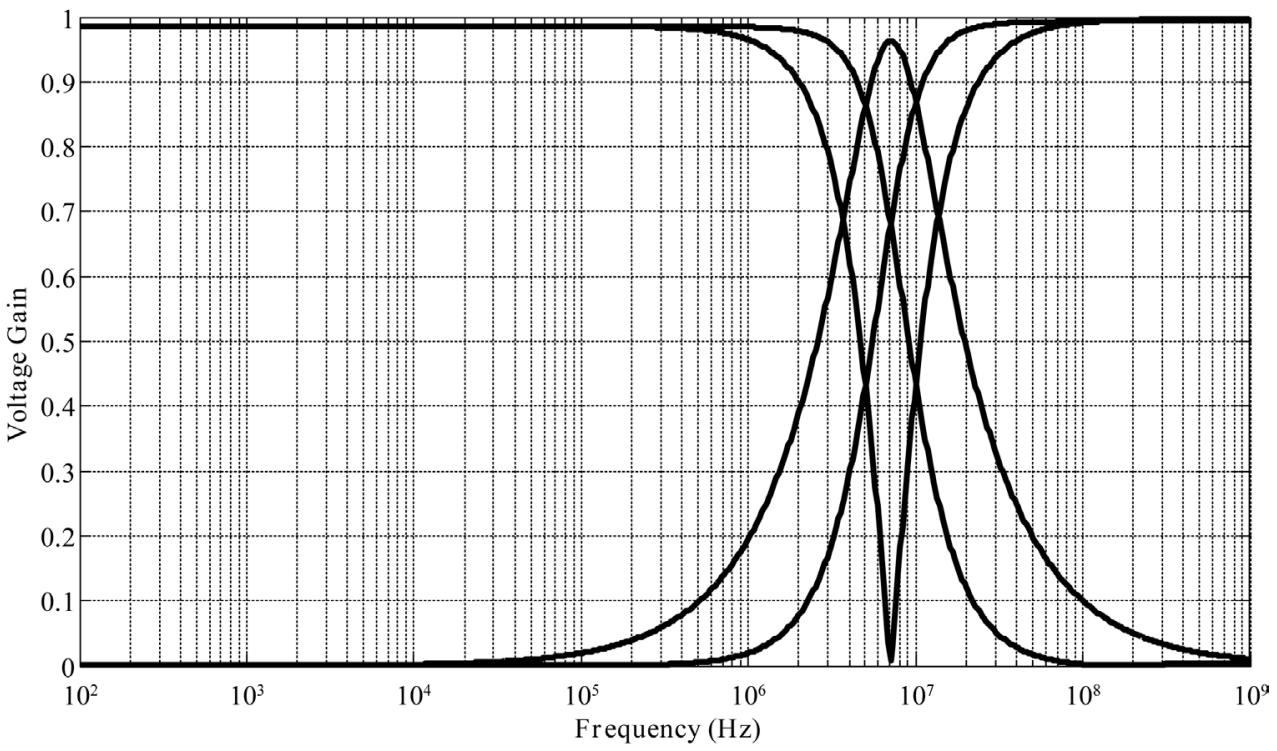

Figure 4. Frequency response.

Table 1. Comparison of proposed biquad with other available MISO-type VM-biquads using a single active device.

\begin{tabular}{ccccc}
\hline Reference & $\begin{array}{c}\text { Number of } \\
\text { resistors used }\end{array}$ & $\begin{array}{c}\text { Number. of } \\
\text { capacitors used }\end{array}$ & $\begin{array}{c}\text { Whether all five filter } \\
\text { functions are realized? }\end{array}$ & $\begin{array}{c}\text { Requirement of matching } \\
\text { conditions/constraints }\end{array}$ \\
\hline$[1]$ & $3 / 2$ & $2 / 3$ & No & No \\
{$[2]$} & 5 & 2 & No & Yes \\
{$[3]$} & 1 & 2 & Yes & No \\
{$[4]$} & 2 & 2 & Yes & Yes \\
{$[5]$} & 3 & 2 & Yes & Yes \\
{$[6]$} & 4 & 4 & Yes & Yes \\
{$[7]$} & 2 & 2 & Yes & Yes \\
{$[8]$} & 2 & 2 & Yes & Yes \\
{$[9]$} & 2 & 2 & Yes & Yes \\
{$[10]$} & 2 & 2 & No & No \\
{$[11]$} & 3 & 2 & No & Yes \\
Proposed & 1 & 2 & No & No \\
\hline
\end{tabular}




\section{Conclusion}

In this paper, an application of VDVTA is proposed in the form of VM-MISO-type biquad using three passive components. The proposed filter can realize the second-order LP, BP, HP and BR responses without changing the circuit topology and without any matching constraint(s). The LP filter response enjoys an additional advantage of having both the capacitors grounded as preferred for integration point of view [15]. The circuit offers low active and passive sensitivities. The SPICE simulation results using TSMC CMOS $0.18 \mu \mathrm{m}$ process confirm the workability of the proposed structure.

\section{References}

[1] Hou, C.L., Huang, C.C., Lan, Y.S., Shaw, J.J. and Chang, C.M. (1999) Current-Mode and Voltage-Mode Universal Biquads Using a Single Current-Feedback Amplifier. International Journal of Electronics, 86, 929-932. http://dx.doi.org/10.1080/002072199132923

[2] Sharma, R.K. and Senani, R. (2003) Multifunction CM/VM Biquads Realized with a Single CFOA and Grounded Capacitors. AEU: International Journal of Electronics and Communications, 57, 301-308. http://dx.doi.org/10.1078/1434-8411-54100176

[3] Prasad, D., Bhaskar, D.R. and Srivastava, M. (2013) Universal Voltage-Mode Biquad Filter Using a VDTA. Indian Journal of Pure and Applied Physics, 51, 864-868.

[4] Sagbas, M. and Koksal, M. (2007) Voltage-Mode Three-Input Single-Output Multifunction Filters Employing Minimum Number of Components. FREQUENZ: Journal of RF-Engineering and Telecommunications (Germany), 61, 8793. http://dx.doi.org/10.1515/FREQ.2007.61.3-4.87

[5] Prasad, D., Bhaskar, D.R. and Singh, A.K. (2009) Multi-Function Biquad Using Single Current Differencing Transconductance Amplifier. Analog Integrated Circuits and Signal Processing (USA), 61, 309-313. http://dx.doi.org/10.1007/s10470-009-9310-1

[6] Keskin, A.U. (2006) Multi-Function Biquad Using Single CDBA. Electrical Engineering, 88, 353-356. http://dx.doi.org/10.1007/s00202-004-0289-4

[7] Herencsar, N., Koton, J., Vrba, K. and Lattenberg, I. (2010) New Voltage-Mode Universal Filter and Sinusoidal Oscillator Using Only Single DBTA. International Journal of Electronics, 97, 365-369. http://dx.doi.org/10.1080/00207210903325229

[8] Tangsrirat, W. and Channumsin, O. (2011) Voltage-Mode Multifunctional Biquadratic Filters Using Single DVCC and Minimum Number of Passive Elements. Indian Journal of Pure and Applied Physics, 49, 703-707.

[9] Kumar, P. and Pal, K. (2008) Universal Biquadratic Filter Using a Single Current Conveyor. Journal of Active and Passive Electronic Devices, 3, 7-16.

[10] Shah, N.A., Rather, M.F. and Iqbal, S.Z. (2005) A Novel Voltage-Mode Universal Filter Using a Single CFA. Journal of Active and Passive Electronic Devices, 1, 183-188.

[11] Chen, H.P. (2010) Single CCII-Based Voltage-Mode Universal Filter. Analog Integrated Circuits and Signal Processing (USA), 62, 259-262. http://dx.doi.org/10.1007/s10470-009-9345-3

[12] Chang, C.M. and Chen, H.P. (2005) Single FDCCII-Based Tunable Universal Voltage-Mode Filter. Circuits, Systems and Signal Processing, 24, 221-227. http://dx.doi.org/10.1007/s00034-004-0422-7

[13] Biolek, D., Senani, R., Biolkova, V. and Kolka, Z. (2008) Active Elements for Analog Signal Processing; Classification, Review and New Proposals. Radioengineering, 17, 15-32.

[14] Shaktour, I.M. (2011) Unconventional Circuit Elements for Ladder Filter Design. Ph.D. Thesis. https://www.vutbr.cz/www_base/zav_prace_soubor_verejne.php?file_id=35975

[15] Bhushan, B. and Newcomb, R.W. (1967) Grounding of Capacitors in Integrated Circuits. Electronics Letters, 3, 148149. http://dx.doi.org/10.1049/el:19670114

[16] Yesil, A., Kacar, F. and Kuntman, H. (2011) New Simple CMOS Realization of Voltage Differencing Transconductance Amplifier and Its RF Filter Application. Radioengineering, 20, 632-637. 